Article

\title{
CaLB Catalyzed Conversion of $\varepsilon$-Caprolactone in Aqueous Medium. Part 1: Immobilization of CaLB to Microgels
}

\author{
Stefan Engel ${ }^{1}$, Heidi Höck ${ }^{2}$, Marco Bocola ${ }^{2}$, Helmut Keul ${ }^{1}$, Ulrich Schwaneberg ${ }^{2}$ \\ and Martin Möller ${ }^{1, *}$ \\ 1 DWI-Leibniz Institute for Interactive Materials and Institute of Technical and Macromolecular Chemistry, \\ RWTH Aachen University, Forckenbeckstraße 50, D-52056 Aachen, Germany; \\ Engel@dwi.rwth-aachen.de (S.E.); Keul@dwi.rwth-aachen.de (H.K.) \\ 2 DWI-Leibniz Institute for Interactive Materials and Institute of Biotechnology, RWTH Aachen University, \\ Forckenbeckstraße 50, D-52056 Aachen, Germany; Hoeck@dwi.rwth-aachen.de (H.H.); \\ M.Bocola@biotec.rwth-aachen.de (M.B.); U.Schwaneberg@biotec.rwth-aachen.de (U.S.) \\ * Correspondence: Moeller@dwi.rwth-aachen.de; Tel.: +49-241-80-23302
}

Academic Editors: Katja Loos and Alexander Böker

Received: 11 August 2016; Accepted: 10 October 2016; Published: 19 October 2016

\begin{abstract}
The enzymatic ring-opening polymerization of lactones is a method of increasing interest for the synthesis of biodegradable and biocompatible polymers. In the past it was shown that immobilization of Candida antarctica lipase B (CaLB) and the reaction medium play an important role in the polymerization ability especially of medium ring size lactones like $\varepsilon$-caprolactone $(\varepsilon-C L)$. We investigated a route for the preparation of compartmentalized microgels based on poly(glycidol) in which CaLB was immobilized to increase its esterification ability. To find the ideal environment for CaLB, we investigated the acceptable water concentration and the accessibility for the monomer in model polymerizations in toluene and analyzed the obtained oligomers/polymers by NMR and SEC. We observed a sufficient accessibility for $\varepsilon-C L$ to a toluene like hydrophobic phase imitating a hydrophobic microgel. Comparing free CaLB and Novozym ${ }^{\circledR} 435$ we found that not the monomer concentration but rather the solubility of the enzyme, as well as the water concentration, strongly influences the equilibrium of esterification and hydrolysis. On the basis of these investigations, microgels of different polarity were prepared and successfully loaded with CaLB by physical entrapment. By comparison of immobilized and free CaLB, we demonstrated an effect of the hydrophobicity of the microenvironment of CaLB on its enzymatic activity.
\end{abstract}

Keywords: enzyme immobilization; microgel; Candida antarctica lipase B; $\varepsilon$-Caprolactone; Novozym ${ }^{\circledR} 435$; polyesterification

\section{Introduction}

The demand for biocompatible and biodegradable materials like polyesters has been greatly increased during the last decades especially due to its versatile applications in the fields of (bio)medicine and tissue engineering [1,2]. For these applications it is a special challenge of our time to substitute organic solvents as reaction medium with "green" solvents like water [3]. Enzymes in general and lipases in particular are specialized for reactions in aqueous medium. In natural environment lipases are known to hydrolyze fats at the lipid-water interface with formation of fatty acids and glycerol [4,5]. In organic solvents it was shown that lipases also catalyze esterification reactions [6] with the formation of polyesters [7]. In order to reduce the use of ecologically harmful organic solvents, which are always found in traces in the final products, we attempt to engineer the micro surrounding 
of the lipase such, that in the future it can be used for the catalysis of polyesterifications in pure water. In the literature, only a few reports can be found on this topic [8-11].

In the field of organic chemistry, the enzymatic (trans) esterification is widely studied since the 1980s [12,13], whereas in polymer chemistry lipases were under investigation for the first time in 1993. The groups of Kobayashi and Kohn reconnoitered independently the mechanism of the enzyme catalyzed ring-opening polymerization (ROP) of cyclic esters [14,15]. In the following years, Kobayashi et al. further compared the esterification ability of macrolides and smaller ring size lactones like $\varepsilon$-CL with various lipases in organic solvent. It was found that macrolides show a much higher reactivity and degree of polymerization compared to $\varepsilon$-CL [16]. This behavior shows an opposing trend in metal catalyzed ROP, where high molecular weights were obtained for lactones with medium ring size while macrolides were less reactive [17-19].

The first few experiments to perform polyesterifications in water were also reported in the 1990s. It was observed that macrolides in contrast to $\varepsilon$-CL can be polymerized due to their insolubility in water. The formation of a monomer emulsion leads to compartmentalization of the reaction medium comparable to nature, where the compartmentalization of a cell enables the enzymatic production of polynucleotides and peptides $[10,11]$. In the miniemulsion the water concentration at the interface (where the lipase is expected to attach, due to its hydrophobic surface around the active site), as well as in the monomer phase, is highly limited and the esterification is the preferred catalyzed reaction of the lipase. Though, compared to the reaction in pure organic solvents the obtained degree of polymerization for macrolides is much lower, e.g., the polymerization of 11-undecanolide (UDL) in water yielded the corresponding polyester with $79 \%$ conversion and $M_{\mathrm{n}} 1300 \mathrm{Da}$ [8]. However, in the case of water miscible lactones like $\varepsilon-C L$, no emulsions are formed and no compartmentalization occurs. Due to the high water concentration in the close environment of both the active site of the lipase and the monomer, hydrolysis of the lactone ring yielding 6-hydroxycaproic acid is the preferably catalyzed reaction. These results show that by changing the microenvironment of the enzyme and the substrate, the catalyzed synthesis can be directed to the desired product. In this case, the hydrolysis-esterification equilibrium can be pushed towards the esterification by using more hydrophobic monomers. In synthetic chemistry the use of miniemulsions as nanoreactors for directing enzymatic catalyzed reactions is a common method, not only for the synthesis of linear aliphatic polyesters [20], but also for the aminolysis of lactones [21] or the preparation of biodegradable pentadecalactone (PDL) nanoparticles [22] among others [23].

When talking about directing of enzymatic catalysis, immobilization is another important method, bringing various benefits like efficient recovery, improving process economy as well as stabilization and protection of the enzyme against exterior influences like $\mathrm{pH}$, solvents or temperature. Especially protection of the enzyme is a very important point regarding the effect of water on the esterification ability of lipases described above. A widely used and commercially available immobilized lipase is Candida antarctica lipase B (CaLB) adsorbed on a macroporous acrylic resin (Novozym $\left.{ }^{\circledR} 435\right)$. Next to its application for aminolysis or transesterification it is the most often used lipase formulation for the enzymatic ROP of lactones in organic solvents and was well studied by various groups [24,25]. Using

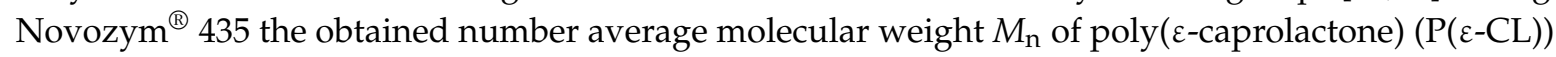
is between 10 and $25 \mathrm{kDa}$ if the polymerization is performed in dry organic media. To the best of our knowledge, this high polymerization ability of CaLB has never been reached by any other immobilized CaLB catalyst and therefore Novozym ${ }^{\circledR} 435$ can be seen as a benchmark for polyesterification in organic solvents. On the other hand, using Novozym ${ }^{\circledR} 435$ in water again the hydrolysis of the ester is the preferred catalyzed reaction and only low molecular weight oligomers are obtained. The reason for the great performance of Novozym ${ }^{\circledR} 435$ in organic solvents and the low degree of polymerization in water has never been discussed in literature so far and will be taken up in the publication in hand. At this point it should be mentioned that by working with Novozym ${ }^{\circledR} 435$ in water we detected traces of a nonionic poly(ethylene oxide/propylene oxide) copolymer surfactant in the reaction products (unpublished results). To our knowledge the presence of the surfactant in Novozym ${ }^{\circledR} 435$ and its role 
on the activity of CaLB has never been explained, however, this observation will not be subject of the present manuscript.

In this publication we will thus focus on the effect of different solvent compositions and of the immobilization of CaLB in microgels by physical entrapment on the hydrolytic and esterification activity. The poly(glycidol) based microgels we will use were developed by our group recently [26,27]. They provide, in terms of hydrophilic-lipophilic balance, an adjustable and compartmentalized structure and therefore offer a high concentration of interfaces, where the polymerization is expected to take place. The reaction products-oligomers and polymers-are analyzed by NMR and SEC measurements. By analyzing the ratio of hydrolysis and esterification product we will investigate the esterification ability of CaLB under varying reaction conditions. Further we will analyze the dispersity of the polymeric products and discuss the activation of the lipase by immobilization as well as the possible coexistence of different active "forms" of CaLB (aggregated, soluble, bound, protected, inhibited) according to the classification described by Fernández-Lafuente et al. [28].

\section{Materials and Methods}

\subsection{Materials and Instrumentation}

$\varepsilon$-Caprolactone (99\%, Alfa Aesar, Karlsruhe, Germany), allyl glycidyl ether (AGE, $>99 \%$, Sigma Aldrich Chemie GmbH, Steinheim, Germany), tert-butyl glycidyl ether (tBGE, 99\%, Sigma Aldrich Chemie GmbH, Steinheim, Germany), toluene (VWR Chemicals, Fontenay-sous-Bais, France), caesium hydroxide (96\%, Alfa Aesar, Karlsruhe, Germany), 2,2-dimethoxy-2-phenylacetophenone (DMPA, 99\%, Sigma Aldrich Chemie GmbH, Steinheim, Germany), sodium dodecyl sulfate (SDS, Bio-Rad Laboratories GmbH, München, Germany), hexadecane (99\%, Sigma Aldrich Chemie GmbH, Steinheim, Germany), 2,2'-(ethylenedioxy)diethanethiol (95\%, Sigma Aldrich, Quimica, Toluca, Mexico), triethylene glycol monomethyl ether (TEGME, >97\%, Merck, Darmstadt, Germany), calcium hydride (93\%, Thermofisher Acros Organics, Geel, Belgium), ethyl vinyl ether (99\%, Sigma Aldrich Chemie GmbH, Steinheim,"Germany) and glycidol (96\%, Sigma Aldrich Chemie GmbH, Steinheim, Germany) were used as received. Ethoxyethyl glycidyl ether (EEGE) was prepared according to Fitton et al. [29]. Toluene, tert-butyl glycidyl ether, allyl glycidyl ether, ethoxyethyl glycidyl ether and $\varepsilon$-caprolactone were dried over $\mathrm{CaH}_{2}$ for $24 \mathrm{~h}$ and distilled under nitrogen atmosphere before use. Novozym ${ }^{\circledR} 435$ (Novozymes A/S, Bagsvaerd, Denmark) was used as received, while CaLB-wt was obtained from c-LEcta (Leipzig, Germany) and purified or produced by ourselves. The protocol for the cloning [30], production and purification of CaLB is attached in the supplementary materials (Section 8).

${ }^{1} \mathrm{H}$ - and ${ }^{13} \mathrm{C}-\mathrm{NMR}$ spectra were recorded on a Bruker Avance III 400 spectrometer (400 MHz and $100 \mathrm{MHz}$, respectively; Bruker Corporation, Billerica, MA, USA) and are reported as follows: chemical shift $\delta$ (ppm) (multiplicity, number of protons, assignment). Chloroform $\left(\mathrm{CDCl}_{3}, \delta \mathrm{H}=7.26 \mathrm{ppm}\right.$, $\delta \mathrm{C}=77.0 \mathrm{ppm})$ was used as an internal standard. Chemical shifts are reported in ppm to the nearest $0.01 \mathrm{ppm}$ for ${ }^{1} \mathrm{H}$ - and the nearest $0.1 \mathrm{ppm}$ for ${ }^{13} \mathrm{C}-\mathrm{NMR}$. The ${ }^{1} \mathrm{H}-\mathrm{NMR}$ spectra for the determination of the partition coefficient of $\varepsilon$-CL were recorded on a Bruker Avance I 600 spectrometer (600 MHz). Water $\left(\mathrm{D}_{2} \mathrm{O}, \delta \mathrm{H}=4.79 \mathrm{ppm}\right)$ and toluene (toluene- $\mathrm{d}_{8}, \delta \mathrm{H}=2.09 \mathrm{ppm}$ ) were used as internal standard. Molecular weights $\left(M_{\mathrm{n}}\right.$ and $\left.M_{\mathrm{W}}\right)$ and molecular weight distributions $(\nexists)$ were determined by size-exclusion chromatography (SEC). The results were evaluated using the PSS WinGPC UniChrom software (Version 8.1.1). SEC analyses were carried out with tetrahydrofuran (THF, HPLC grade, Carl Roth, Karlsruhe, Germany) as eluent using a HPLC pump (PU-2080plus, Jasco, Gross-Umstadt, Germany) equipped with a refractive index detector (RI-2031plus, Jasco, Gross-Umstadt, Germany). The sample solvent contained $250 \mathrm{mg} \cdot \mathrm{mL}^{-1}$ 3,5-di-tert-4-butylhydroxytoluene (BHT, $\geq 99 \%$, Sigma Aldrich Chemie $\mathrm{GmbH}$, Steinheim, Germany) as internal standard. One pre-column $(8 \mathrm{~mm} \times 50 \mathrm{~mm})$ and four SDplus gel columns $(8 \mathrm{~mm} \times 300 \mathrm{~mm}$, SDplus, MZ Analysentechnik, Mainz, Germany) were applied at a flow rate of $1.0 \mathrm{~mL} \cdot \mathrm{min}^{-1}$ at $20^{\circ} \mathrm{C}$. The diameter of the gel particles measured $5 \mu \mathrm{m}$, the 
nominal pore widths were $50,10^{2}, 10^{3}$ and $10^{4} \AA$. Calibration was achieved using narrow distributed poly(methyl methacrylate) standards (PSS Polymer Standards Service GmbH, Mainz, Germany) from 600 to 576,000 Da.

The hydrolytic activity of the free and immobilized CaLB was determined by triple determination by a para-nitrophenyl butyrate ( $p N P B$ ) assay. The microgel sample was diluted to linear range of the assay. The activity was determined by addition of triethanolamine (TEA) buffer ( $90 \mu \mathrm{L}, 0.1 \mathrm{M}, \mathrm{pH} 7.5)$ to the diluted sample $(10 \mu \mathrm{L})$ and freshly prepared substrate solution (TEA buffer $(100 \mu \mathrm{L})$ containing $p$ NPB $(0.5 \mathrm{mM})$ and acetonitrile $(10 \%, v / v))$. The release of para-nitrophenolate was recorded by measuring the absorption at $410 \mathrm{~nm}$ at room temperature over $8 \mathrm{~min}$ on a microtiter plate reader (Omega FLUOstar, BMG LABTECH, Ortenberg, Germany).

The amino acid analysis was performed after hydrolysis of the enzyme by capillary-gas liquid chromatography with mass-spectrometry coupling (GC-MS) (triple determination). Therefore the CaLB loaded microgel $(1 \mathrm{~mL})$ was mixed with conc. $\mathrm{HCl}(1: 1 v / v)$ in an ampoule. After addition of a $1 \mathrm{M}$ phenole solution in $6 \mathrm{M} \mathrm{HCl}(20 \mu \mathrm{L})$ the mixture was degassed, the ampoule sealed under vacuum and heated to $110{ }^{\circ} \mathrm{C}$ for $24 \mathrm{~h}$. The aqueous solution was decanted from the microgel residues and the water was removed by evaporation. The hydrolysates were washed twice with water, before they were incubated in pyridine $(1 \mathrm{~mL})$ at $60{ }^{\circ} \mathrm{C}$. The cooled solutions were centrifuged ( $1 \mathrm{~min}, 13,000 \mathrm{rpm}$ ) twice and the respective supernatants were transferred in a volumetric flask. The combined collected supernatants were diluted with pyridine to a final volume of $2 \mathrm{~mL}$. For the preparation of the tert-butyldimethylsilyl (TBDMS) derivates the hydrolysate solution $(200 \mu \mathrm{L})$ was mixed with $N$-methyl- $N$-tert-butyldimethylsilyl-trifluoroacetamide (MBDSTFA, $400 \mu \mathrm{L}$ ) and pyridine $(400 \mu \mathrm{L})$ and heated for $1 \mathrm{~h}$ at $60^{\circ} \mathrm{C}$. After cooling to room temperature the samples were analyzed by GC-MS.

GC-MS was performed at a Perkin Elmer Clarus 600 Mass Spectrometer (Perkin Elmer Inc., Waltham, MA, USA). Aliquots of $1 \mu \mathrm{L}$ of the amino acid TBDMS solutions were injected at $280{ }^{\circ} \mathrm{C}$ and chromatographed on a Phenomenex 5\% diphenyl $/ 95 \%$ dimethyl polysiloxane MS capillary (30 m, $250 \mu \mathrm{m} \mathrm{ID}, 0.25 \mu \mathrm{m}$ film). The initial oven temperature was $80^{\circ} \mathrm{C}$ and a temperature gradient with a heating rate of $3{ }^{\circ} \mathrm{C} / \mathrm{min}$ up to $300{ }^{\circ} \mathrm{C}$ was run. The carrier gas, helium, was set to $1 \mathrm{~mL} / \mathrm{min}$ with $10 \mathrm{~mL} / \mathrm{min}$ split at the injector port. The mass device was operated in the full scan mode with electron impact ionization and masses recorded from 45 to $620 \mathrm{Da}$; the transfer line was held at $200{ }^{\circ} \mathrm{C}$ and the source temperature at $240^{\circ} \mathrm{C}$.

\subsection{Partition Coefficient of $\varepsilon$ - $C L$ in $D_{2} \mathrm{O} /$ Toluene- $d_{8}$}

$\mathrm{D}_{2} \mathrm{O}(1 \mathrm{~mL})$, toluene- $\mathrm{d}_{8}(1 \mathrm{~mL})$ and $\varepsilon-\mathrm{CL}(80 \mu \mathrm{L})$ were mixed in a $5 \mathrm{~mL}$ glass vial with screw cap. The exact masses of all components were weighed and are shown in Table S1. The mixtures were heated for $12 \mathrm{~h}$ at various temperatures $\left(T=25,35,45\right.$ and $\left.55^{\circ} \mathrm{C}\right)$ under vigorous stirring. Samples of $500 \mu \mathrm{L}$ were taken out of both phases at the particular temperature and weighed in a NMR tube. As a standard, dioxane $(8 \mu \mathrm{L})$ was added to each NMR tube. The ${ }^{1} \mathrm{H}-\mathrm{NMR}$ spectra were measured at the respective temperatures. ${ }^{1} \mathrm{H}-\mathrm{NMR}\left(600 \mathrm{MHz}, \mathrm{D}_{2} \mathrm{O}\right)$ (Figure $\left.\mathrm{S} 1\right): \delta=4.38-4.36\left(\mathrm{~m}, 2 \mathrm{H},-\mathrm{CH}_{2} \mathrm{O}-\right)$, $3.77\left(\mathrm{~s}, 8 \mathrm{H}\right.$, dioxane), 2.72-2.70 (m, 2H, $\left.-\mathrm{CH}_{2} \mathrm{CO}-\right), 1.87-1.84\left(\mathrm{~m}, 2 \mathrm{H},-\mathrm{CH}_{2} \mathrm{CH}_{2} \mathrm{O}-\right), 1.81-1.77(\mathrm{~m}, 2 \mathrm{H}$, $\left.-\mathrm{CH}_{2} \mathrm{CH}_{2} \mathrm{CO}-\right)$, $1.75-1.72\left(\mathrm{~m}, 2 \mathrm{H},-\mathrm{CH}_{2} \mathrm{CH}_{2} \mathrm{CH}_{2}-\right)$ ppm. ${ }^{1} \mathrm{H}-\mathrm{NMR}$ (600 MHz, toluene- $d_{8}$ ) (Figure $\mathrm{S} 2$ ): $\delta=3.58-3.57\left(\mathrm{~m}, 2 \mathrm{H},-\mathrm{CH}_{2} \mathrm{O}-\right), 3.35\left(\mathrm{~s}, 8 \mathrm{H}\right.$, dioxane), 2.17-2.15 (m, 2H, $\left.-\mathrm{CH}_{2} \mathrm{CO}-\right), 1.27-1.23(\mathrm{~m}, 2 \mathrm{H}$, $\left.-\mathrm{CH}_{2} \mathrm{CH}_{2} \mathrm{O}-\right)$, $1.23-1.20\left(\mathrm{~m}, 2 \mathrm{H},-\mathrm{CH}_{2} \mathrm{CH}_{2} \mathrm{CO}-\right), 1.15-1.11\left(\mathrm{~m}, 2 \mathrm{H},-\mathrm{CH}_{2} \mathrm{CH}_{2} \mathrm{CH}_{2}-\right)$ ppm.

\subsection{Enzymatic Polymerization of $\mathcal{E}-C L$ in Water, Toluene and Bulk}

In a $25 \mathrm{~mL}$ flame dried Schlenk tube free CaLB $(1 \mathrm{mg})$ was dissolved in a mixture of $\varepsilon$-CL (water content: $1532 \mathrm{ppm}$ ) and toluene (water content: $266 \mathrm{ppm}$ ) and $\mathrm{H}_{2} \mathrm{O}$ respectively. The overall mass was $4 \mathrm{~g}$ in which the mass ratio of the components was varied as shown in Table S2. After stirring the solutions for $46 \mathrm{~h}$ at $50{ }^{\circ} \mathrm{C}$ the solvent was removed and the product dried in vacuum. The product was analyzed without further purification. ${ }^{1} \mathrm{H}-\mathrm{NMR}\left(400 \mathrm{MHz}, \mathrm{D}_{2} \mathrm{O}\right)$ (Figure $\left.\mathrm{S} 4\right): \delta=4.16-4.14(\mathrm{t}, 2 \mathrm{H}$, 
1a), 3.99-3.95 (t, 2H, 1c), 3.56-3.53 (t, 4H, 1b), 2.57-2.54 (t, 2H, 2a), 2.27-2.20 (m, 4H, 2b, 2c), $1.77(\mathrm{~m}, 2 \mathrm{H}$, 3a), $1.68(\mathrm{~m}, 4 \mathrm{H}, 4 \mathrm{a}+5 \mathrm{a}), 1.56(\mathrm{~m}, 8 \mathrm{H}, 3 \mathrm{~b}, 3 \mathrm{c}, 4 \mathrm{~b}, 4 \mathrm{c}), 1.30(\mathrm{~m}, 4 \mathrm{H}, 5 \mathrm{~b}, 5 \mathrm{c})$ ppm. Exemplarily the SEC traces of sample No. 2.4 and 2.7 of Table S2 are shown in Figure S3.

\subsection{Enzymatic Polymerization of $\varepsilon-C L$ in Toluene with Varying Water Concentrations}

In a $25 \mathrm{~mL}$ flame dried Schlenk tube free CaLB $(1 \mathrm{mg})$ or Novozym ${ }^{\circledR} 435(10 \mathrm{mg}, 1 / 10 \mathrm{wt} / \mathrm{wt})$ was dispersed in a mixture of anhydrous and water saturated toluene in different ratios with an overall volume of $3.2 \mathrm{~g}$ (see Tables S3-S8). $\varepsilon$-CL monomer $(0.8 \mathrm{~g})$ was added and the solutions were stirred for $46 \mathrm{~h}$ at $50{ }^{\circ} \mathrm{C}$. The solvent was evaporated and the product was dried in vacuum. The product was analyzed by NMR and SEC without further purification.

\subsection{Synthesis of $P(E E G E)_{0.8}-b-P(A G E)_{0.2} 1$}

Caesium hydroxide $(0.175 \mathrm{~g}, 1.03 \mathrm{mmol}, 1 / 25 \mathrm{eq}$.$) and triethylene glycol monomethylether$ $\left(0.170 \mathrm{~g}, 1.03 \mathrm{mmol}, 1 / 25 \mathrm{eq}\right.$.) were dissolved in benzene $(5 \mathrm{~mL})$ and stirred at $60{ }^{\circ} \mathrm{C}$ for $30 \mathrm{~min}$. The benzene/water azeotrope was removed by distillation at $90{ }^{\circ} \mathrm{C}$ and the residue was dried for another $3 \mathrm{~h}$ at $90{ }^{\circ} \mathrm{C}$. Ethoxyethyl glycidyl ether $(2.90 \mathrm{~g}, 19.83 \mathrm{mmol}, 0.8$ eq. $)$ was added at room temperature and the reaction mixture was heated to $40^{\circ} \mathrm{C}$. After $17 \mathrm{~h}$ allyl glycidyl ether $(0.554 \mathrm{~g}$, $4.85 \mathrm{mmol}, 0.2$ eq.) was added and the temperature was increased to $50{ }^{\circ} \mathrm{C}$. After $24 \mathrm{~h}$ and full conversion the polymerization was terminated by the addition of ethanol $(1 \mathrm{~mL})$. The polymer solution in ethanol was precipitated in cold water, filtrated and dried in vacuum. The product was obtained as orange oil. Yield $2.34 \mathrm{~g}(68 \%) .{ }^{1} \mathrm{H}-\mathrm{NMR}\left(400 \mathrm{MHz}, \mathrm{CDCl}_{3}\right)$ (Figure S5): $\delta=5.86\left(\mathrm{~m}, 1 \mathrm{H},-\mathrm{OCH}_{2} \mathrm{CHCH}_{2}\right)$, 5.26-5.13 (dd, $\left.2 \mathrm{H},-\mathrm{OCH}_{2} \mathrm{CHCH}_{2}\right), 4.68\left(\mathrm{~m}, 1 \mathrm{H}, \mathrm{CH}_{3} \mathrm{CH}-\right), 3.96\left(\mathrm{~d}, 2 \mathrm{H},-\mathrm{OCH}_{2} \mathrm{CHCH}_{2}\right), 3.63-3.44$ (m, $\left.12 \mathrm{H},-\mathrm{CH}_{2} \mathrm{CHO}-_{\text {(backbone) }},-\mathrm{CH}_{2} \mathrm{CHO}-_{\text {(backbone) }},-\mathrm{OCH}_{2} \mathrm{CH}_{\text {(backbone) }} \mathrm{CH}_{2} \mathrm{O}-,-\mathrm{OCH}_{2} \mathrm{CH}_{3}\right), 3.35$ (s, $\left.3 \mathrm{H},-\mathrm{O}-\mathrm{CH}_{3 \text { (Initiator) }}\right) 1.28-1.27\left(\mathrm{~d}, 3 \mathrm{H},-\mathrm{CHCH}_{3}\right), 1.18\left(\mathrm{t}, 3 \mathrm{H},-\mathrm{OCH}_{2} \mathrm{CH}_{3}\right)$ ppm. ${ }^{13} \mathrm{C}-\mathrm{NMR}(100 \mathrm{MHz}$, $\mathrm{CDCl}_{3}$ ) (Figure S6): $\delta=134.8,117.1,99.8,78.9,72.4-72.0,70.1,65.1-64.8,60.9,59.1,19.9,15.4$ ppm. The SEC trace is shown in Figure S7.

\subsection{Synthesis of $P(t B G E)_{0.8}-b-P(A G E)_{0.2} 2$}

The $\mathrm{P}(t \mathrm{BGE})_{0.8}-\mathrm{b}-\mathrm{P}(\mathrm{AGE})_{0.2}$ prepolymer was prepared analogue to the previously described procedure using caesium hydroxide $(0.195 \mathrm{~g}, 1.15 \mathrm{mmol}, 1 / 25 \mathrm{eq}$.$) , triethylene glycol monomethylether$ ( $0.189 \mathrm{~g}, 1.15 \mathrm{mmol}, 1 / 25 \mathrm{eq}.), t \mathrm{BGE}(3.019 \mathrm{~g}, 23.19 \mathrm{mmol}, 0.8 \mathrm{eq}$.$) and AGE (0.629 \mathrm{~g}, 5.51 \mathrm{mmol}, 0.2)$. Yield $3.11 \mathrm{~g}(85 \%) .{ }^{1} \mathrm{H}-\mathrm{NMR}\left(400 \mathrm{MHz}, \mathrm{CDCl}_{3}\right.$ ) (Figure $\left.\mathrm{S} 8\right): \delta=5.87\left(\mathrm{~m}, 1 \mathrm{H},-\mathrm{OCH}_{2} \mathrm{CHCH}_{2}\right), 5.27-5.13$ $\left(\mathrm{dd}, 2 \mathrm{H},-\mathrm{OCH}_{2} \mathrm{CHCH}_{2}\right), 3.98\left(\mathrm{~d}, 2 \mathrm{H},-\mathrm{OCH}_{2} \mathrm{CHCH}_{2}\right), 3.64-3.38\left(\mathrm{~m}, 10 \mathrm{H},-\mathrm{CH}_{2} \mathrm{CHO}-\right.$ (backbone), $\left.-\mathrm{OCH}_{2} \mathrm{CHO}-_{\text {(backbone) }},-\mathrm{O}-\mathrm{CH}_{2} \mathrm{CH}_{(\text {backbone) }} \mathrm{CH}_{2} \mathrm{O}-\right)$ ) 3.37 (s, 3H, $\left.-\mathrm{O}-\mathrm{CH}_{3 \text { (Initiator) }}\right), 1.16$ (s, 9H, -O-C $\left.\left(\mathrm{CH}_{3}\right)_{3}\right)$ ppm. ${ }^{13} \mathrm{C}-\mathrm{NMR}\left(100 \mathrm{MHz}, \mathrm{CDCl}_{3}\right.$ ) (Figure S9): $\delta=134.9,116.7,79.3-79.0,72.7,72.2,71.9$, 70.8-70.1, 62.0, 59.0, 27.5 ppm. The SEC trace is shown in Figure S10.

\subsection{Synthesis of Polyglycidol Based Microgels with in Situ Entrapment of CaLB}

The procedure for the synthesis of polyglycidol based microgels was reported in detail by our group $[26,27]$ and is complemented by the addition of CaLB here. Exemplarily the procedure for the preparation of MG 1 is explained. $\mathrm{P}(\mathrm{EEGE})_{0.8}-b-\mathrm{P}(\mathrm{AGE})_{0.2} \mathbf{1}(1 \mathrm{~g}, 1.428 \mathrm{mmol}$ allyl groups, 1 eq.), free CaLB (10 mg), 2,2'-(ethylenedioxy)diethanethiol ( $0.143 \mathrm{~g}$, $0.785 \mathrm{mmol} ., 0.55 \mathrm{eq}$.$) , hexadecane (0.082 \mathrm{~g})$ and 2,2-dimethoxy-2-phenylacetophenone (0.036 g) were dissolved in toluene ( $3.48 \mathrm{~g})$. A solution of sodium dodecylsulfate $(0.005 \mathrm{~g})$ in water $(16 \mathrm{~g})$ was filtered and added to the organic phase. After a miniemulsion was prepared with a Branson Ultrasonifier 450 for $15 \mathrm{~min}$ (output control 3, duty cycle $50 \%)$ the emulsion was irradiated with a UV-LED cube $(\lambda=365 \mathrm{~nm})$ for $2 \mathrm{~h}$ under stirring with a mechanical stirrer (1000 rpm). The microgel was purified by dialysis against water (molecular weight cutoff: $100 \mathrm{kDa}$ ). The enzyme concentration in the microgel was determined by amino acid analysis and measurements of the hydrolytic activity before and after dialysis. 
The MG 2 as well as the CaLB free microgels MG 1.1 and MG 2.1 were prepared analogue to the previously described procedure (Tables S9 and S10).

\subsection{Enzymatic Polymerization of $\varepsilon-C L$ in Toluene with $M G_{t o l} 2$}

MG 2 was transferred to toluene by dialysis first against THF and afterwards against toluene. In a $25 \mathrm{~mL}$ flame dried Schlenk tube $\mathrm{MG}_{\text {tol }} 2$ (2.63 g, water content: $\left.530 \mathrm{ppm}\right)$ was mixed with anhydrous toluene ( $0.56 \mathrm{~g}$, water content: $12 \mathrm{ppm})$ and $\varepsilon$-CL monomer $(0.83 \mathrm{~g}$, water content: $39 \mathrm{ppm})$. The solution was stirred for $46 \mathrm{~h}$ at $50{ }^{\circ} \mathrm{C}$. The solvent was evaporated and the product was dried in vacuum. The product was analyzed by NMR and SEC without further purification. The SEC trace and the ${ }^{1} \mathrm{H}-\mathrm{NMR}$ spectrum are shown in Figure S11.

A reference experiment with the enzyme free MG 2.1 was performed analogue to the previously described procedure (Figure S12).

\section{Results and Discussion}

$\varepsilon$-Caprolactone is converted in aqueous media in the presence of free or immobilized CaLB as catalyst either by hydrolysis or by ring opening esterification to form 6-hydroxy caproic acid and/or corresponding oligomers (Scheme 1). In the publication in hand we investigate the influence of the microenvironment of the lipase on the hydrolysis-esterification balance by immobilization.

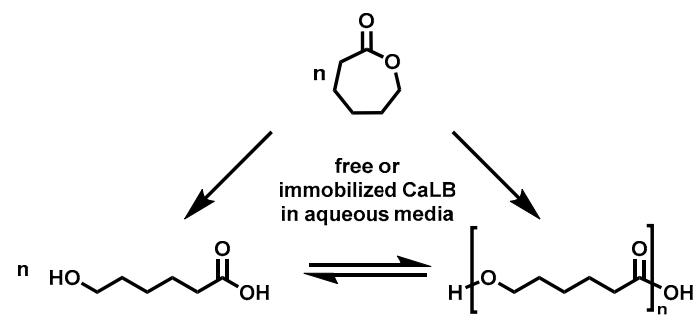

Scheme 1. Conversion of $\varepsilon$-CL to 6-hydroxy caproic acid by hydrolysis or to oligo(caprolactone) by esterification catalyzed by free or immobilized CaLB in aqueous media.

Prior to the immobilization of CaLB in compartmentalized microgels by physical entrapment and the investigation of its effect on the catalytic activity, we will describe the influence of different parameters on the conversion of $\varepsilon$-CL: (i) The partition coefficient of $\varepsilon$-CL in a toluene/water mixture is determined to proof the accessibility of the monomer in hydrophobic domains, which are provided by the microgel to enable esterification; (ii) The influence of the $\varepsilon$-CL concentration for the conversion with free CaLB in toluene is investigated and compared to water as reaction medium; (iii) The effect of increasing water content in the hydrophobic phase will be described by performing the polymerization of $\varepsilon-C L$ in toluene with varying water concentrations.

\subsection{Distribution of $\varepsilon$-CL in a Hydrophilic/Hydrophobic Environment}

For increasing the esterification ability of CaLB it is required to ensure that the catalysis takes place in or at the interface of a hydrophobic environment, where the monomer has to be present to a sufficient part in the hydrophobic domain. Imitating the hydrophilic/hydrophobic domains in an amphiphilic microgel we determined the distribution of $\varepsilon$-CL between toluene- $\mathrm{d}_{8}$ and $\mathrm{D}_{2} \mathrm{O}$ at certain temperatures by ${ }^{1} \mathrm{H}-\mathrm{NMR}$ spectroscopy with dioxane as a standard (see also Table S1). Figure 1 shows a portion of $\sim 70 \mathrm{wt} \% \varepsilon$-CL in the toluene- $\mathrm{d}_{8}$ phase, which stays constant over a temperature range from 25 to $55{ }^{\circ} \mathrm{C}$. In analogy to the common $\log P_{\mathrm{O}, \mathrm{w}}$ value as a description of the average partition coefficient here the $\log P_{\mathrm{Tol}, \mathrm{D} 2 \mathrm{O}}$ is determined by Equation (1) and we obtained a $\log P_{\mathrm{Tol}, \mathrm{D} 2 \mathrm{O}}$ of 0.37 for $\varepsilon$-CL.

$$
\log P_{\mathrm{Tol}, \mathrm{D}_{2} \mathrm{O}}=\log \frac{c_{\mathrm{Tol}}^{\mathcal{\varepsilon}-\mathrm{CL}}}{c_{\mathrm{D}_{2} \mathrm{O}}^{\varepsilon-\mathrm{CL}}}
$$


The value lower than 1 shows the lipophilic behavior of the $\varepsilon$-CL. Since the polymerization reaction is perfomed within the observed temperature range at $50{ }^{\circ} \mathrm{C}$ a sufficient monomer concentration in a toluene like hydrophobic microgel is ensured.

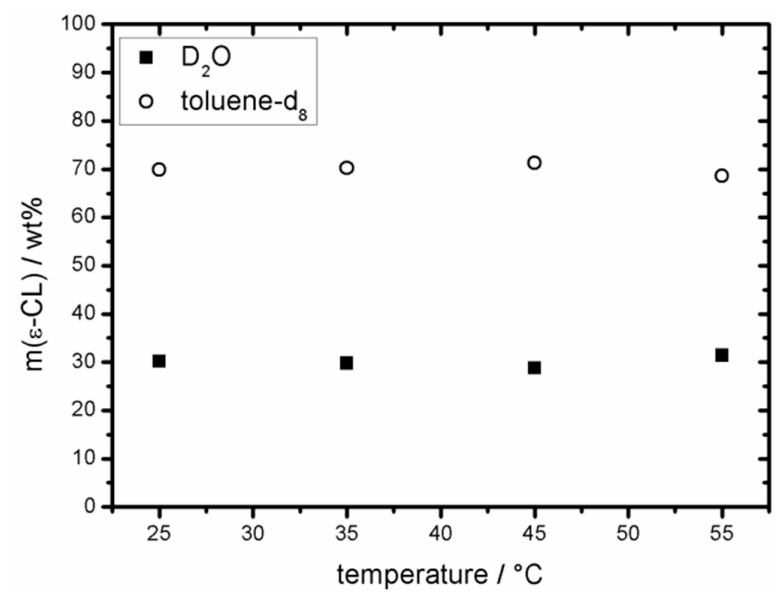

Figure 1. Distribution of $\varepsilon$-CL in toluene- $\mathrm{d}_{8}$ and $\mathrm{D}_{2} \mathrm{O}$ measured by ${ }^{1} \mathrm{H}-\mathrm{NMR}$ spectroscopy at temperatures from 25 to $55^{\circ} \mathrm{C}$.

\subsection{Effect of the $\varepsilon$-CL Concentration on the Esterification Ability of Non-Immobilized CaLB}

The esterification ability of non-immobilized (free) CaLB as a function of the monomer concentration $c(\varepsilon-C L)$ was investigated both in water and in toluene. Using $\varepsilon$-CL concentrations from $20 \mathrm{wt} \%$ up to bulk conditions the products were analyzed in terms of conversion to oligomers $C_{\text {oligo }}$ (fraction of $\varepsilon$-CL repeating units) by ${ }^{1} \mathrm{H}-\mathrm{NMR}$ and their number average molecular weight $M_{\mathrm{n}}$ by SEC (Table 1). The ${ }^{1} \mathrm{H}-\mathrm{NMR}$ spectra and SEC traces as well as the calculation of $C_{\text {oligo }}$ are shown in Section 2 in the supplementary information. Important to note is, that the monomer and the toluene were not anhydrous in these experiments and contained 1530 and 266 ppm water respectively.

Table 1. CaLB catalyzed ROP of $\varepsilon$-CL in bulk, water and toluene with varying $\varepsilon$-CL concentrations; conversion to oligomers and their molecular weights.

\begin{tabular}{cccccc}
\hline Solvent & Fraction of $\varepsilon$-CL & Fraction of solvent & $\mathbf{H}_{\mathbf{2}} \mathbf{O}$ Content/ppm & $\boldsymbol{C}_{\mathbf{~ o l i g o}} / \mathbf{m o l}$ \% & $\mathbf{M}_{\mathbf{n}} / \mathbf{D a}^{(\mathbf{1})}$ \\
\hline bulk $\varepsilon-\mathrm{CL}$ & 1 & 0 & 1,530 & 1 & $-(3)$ \\
$\mathrm{H}_{2} \mathrm{O}$ & 0.8 & 0.2 & - & 29 & $-(3)$ \\
$\mathrm{H}_{2} \mathrm{O}$ & 0.5 & 0.5 & - & 20 & $-(3)$ \\
$\mathrm{H}_{2} \mathrm{O}$ & 0.2 & 0.8 & - & 8 & $-(3)$ \\
toluene & 0.8 & 0.2 & 1,280 & 2 & $-(3)$ \\
toluene & 0.5 & 0.5 & 900 & 16 & 630 \\
toluene & 0.2 & 0.8 & 530 & 75 & 940 \\
\hline
\end{tabular}

(1) fraction of $\varepsilon$-CL repeating units determined by ${ }^{1} \mathrm{H}-\mathrm{NMR}$ spectroscopy in $\mathrm{CDCl}_{3}$; ${ }^{(2)} \mathrm{SEC}$ in $\mathrm{THF}$; (3) low intensity signal $(<600 \mathrm{Da})$ beyond the calibration range.

First, regarding the esterification in water (Figure 2a), the conversion of $\varepsilon$-CL to oligomers for all monomer concentrations is rather low and can only be observed in the ${ }^{1} \mathrm{H}-\mathrm{NMR}$ spectrum. With increasing $c(\varepsilon-C L)$ from 20 to $80 \mathrm{wt} \%$ and therefore simultaneously decreasing the water content in the reaction, the fraction of $\varepsilon$-CL repeating units increases from 8 to $29 \mathrm{~mol} \%$. However, performing the reaction in bulk another important parameter for the activity of enzymes comes into play. While CaLB is well soluble in water with up to $80 \mathrm{wt} \%$ of $\varepsilon$-CL, coagulation is observed in pure $\varepsilon$-CL. This deactivated form of CaLB does no longer catalyze any conversion of $\varepsilon$-CL, both in terms of hydrolysis and esterification. Compared to the reaction in water, in toluene an inverse trend is found (Figure $2 \mathrm{~b})$. At low $c(\varepsilon-C L)$ a high conversion to oligomers with a fraction of $\varepsilon$-CL repeating units 
about $75 \mathrm{~mol} \%$ with $M_{\mathrm{n}} 940 \mathrm{Da}$ is observed. This is explained by the low water concentration leading to less hydrolytic activity. However, with increasing $c(\varepsilon-C L)$ also the water content in the reaction increases, due to its presence in the monomer $(1530 \mathrm{ppm})$. This results in a huge decrease of both $C_{\text {oligo }}$ and $M_{\mathrm{n}}$. These investigations of a maximum esterification ability of free CaLB at around $20 \mathrm{wt} \% \varepsilon-\mathrm{CL}$ are in good agreement with the investigations of Gross et al. They observed the highest conversions and molecular weights for Novozym ${ }^{\circledR} 435$ catalyzed polyesterifications in dry toluene at $30 \mathrm{wt} \%$ $\varepsilon$-CL [31]. The shift of the maximum is ascribed to effects of immobilization, e.g., it is expected, that the coagulation of the lipase is prevented by immobilization. This issue will be discussed later (Section 3.3) in this publication.

In this section, we showed the inverse dependency of the monomer concentration in water and toluene to the esterification ability of free CaLB. The observed trends are less dependent to the concentration of the monomer itself; rather more important is the strong influence of the enzyme solubility and the water content in the direct environment of the monomer and the enzyme. In toluene with a water content of $530 \mathrm{ppm}$ the highest degree of esterification is observed resulting in oligo(caprolactone) with a molecular weight of $940 \mathrm{Da}$.

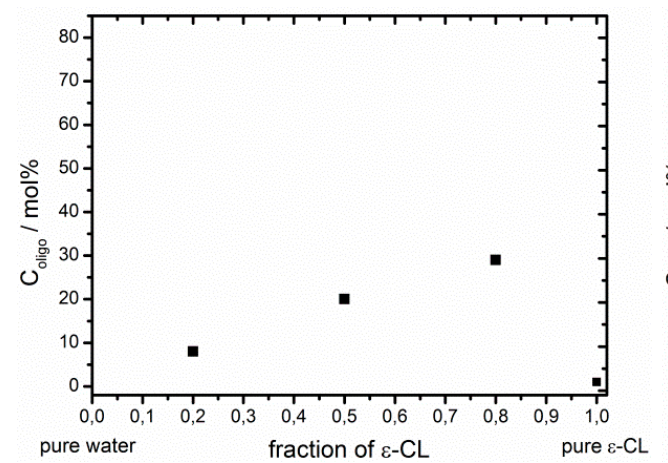

(a)

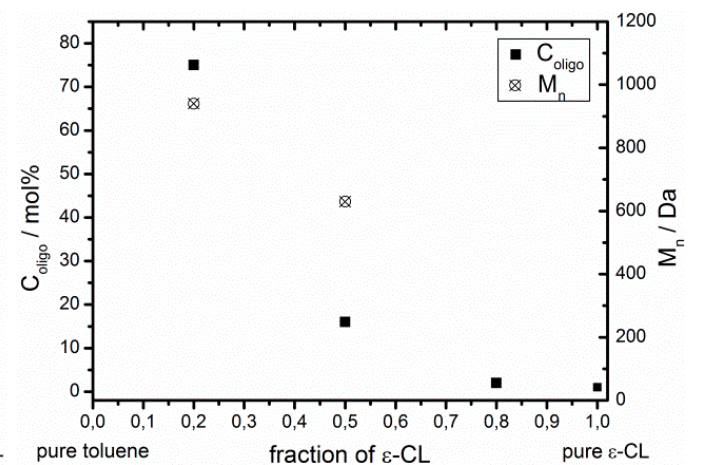

(b)

Figure 2. Conversion to oligomeric products $C_{\text {oligo }}$ determined by ${ }^{1} \mathrm{H}-\mathrm{NMR}$ spectroscopy and $M_{\mathrm{n}}$ values by SEC for the CaLB catalyzed polyesterification of $\varepsilon$-CL in (a) water and (b) toluene with varying $\varepsilon$-CL concentrations (water content $\varepsilon$-CL: 1530 ppm, toluene: 266 ppm).

\subsection{Acceptable Water Concentration in the Hydrophobic Domain}

Detailed investigations for the optimal water concentration in the hydrophobic domain were performed by studying the esterification of $\varepsilon-C L$ in toluene with varying water content. Considering the former results, the chosen $\varepsilon$-CL concentration was $20 \mathrm{wt} \%$ for all experiments and the free CaLB and Novozym ${ }^{\circledR} 435$ were used as catalysts. The average of triple determination of the molecular weights and the dispersity $Đ$ of $\mathrm{P}(\varepsilon-\mathrm{CL})$ are shown in Table 2; the results for each particular experiment are summarized in Tables S3-S8. In Figure 3 the obtained molecular weights and dispersities are plotted against the water content for both free CaLB and Novozym ${ }^{\circledR} 435$. As it was expected, for Novozym ${ }^{\circledR} 435$ the obtained molecular weigths were in general much higher (up to $M_{n} 7700 \mathrm{Da}$ ) than for the free CaLB (up to $M_{\mathrm{n}} 1160 \mathrm{Da}$ ). While the degree of polymerization stays almost constant for free CaLB, for Novozym ${ }^{\circledR} 435$ an interesting trend with increasing water content is found. On the one hand the number average molar mass increases with increasing water content from $6000 \mathrm{Da}$ to $7700 \mathrm{Da}$, while on the other hand the mass average molar mass decreases starting at 25,000 Da at low water content and becoming 17,500 Da at $440 \mathrm{ppm}$ water. In consequence, the dispersity decreases from 4 and converges to 2 .

Two exemplary molecular weight distributions of the $\mathrm{P}(\varepsilon-\mathrm{CL})$ obtained with free CaLB and Novozym ${ }^{\circledR} 435$ are analyzed. The SEC trace of the polymerization with free CaLB and a water content of 263 ppm is shown in Figure 4 (also Table S5, No. 4). It shows a high intensity signal for $\varepsilon$-CL (77\%), a small signal for the 6-hydroxycaproic acid (6\%) and an oligomer distribution with $M_{\mathrm{n}} 1390 \mathrm{Da}$ and 
$Ð 1.5(17 \%)$. In accord with the SEC data, the ${ }^{1} \mathrm{H}-\mathrm{NMR}$ analysis shows a conversion to polymeric products of only $19 \mathrm{~mol} \%$ demonstrating the low conversion with free CaLB.

Table 2. Enzymatic ROP of $\varepsilon$-CL in toluene with varying water content using free CaLB and Novozym ${ }^{\circledR}$ 435 as catalyst ${ }^{(1)}$; results of SEC analyses.

\begin{tabular}{|c|c|c|c|c|c|c|c|}
\hline \multirow{2}{*}{$\begin{array}{l}\text { Toluene } \\
\text { (Dry)/\% }\end{array}$} & \multirow{2}{*}{$\begin{array}{c}\text { Toluene (water } \\
\text { saturated)/\% }\end{array}$} & \multicolumn{3}{|c|}{ Experiments with free CaLB } & \multicolumn{3}{|c|}{ Experiments with Novozym ${ }^{\circledR} 435$} \\
\hline & & $\begin{array}{c}\text { Total } \mathrm{H}_{2} \mathrm{O} \\
\text { content/ppm }\end{array}$ & $M_{\mathrm{n}} / \mathrm{Da}{ }^{(3)}$ & $\bigoplus^{(3)}$ & $\begin{array}{c}\text { Total } \mathrm{H}_{2} \mathrm{O} \\
\text { content/ppm }\end{array}$ & $M_{\mathrm{n}} / \mathrm{Da}{ }^{(3)}$ & $\boxplus^{(3)}$ \\
\hline 100 & 0 & 17 & 1,090 & 1.3 & 12 & 6,400 & 4.1 \\
\hline 80 & 20 & 85 & 1,060 & 1.5 & 92 & 6,000 & 4.3 \\
\hline 60 & 40 & 156 & 1,160 & 1.5 & 178 & 6,000 & 3.4 \\
\hline 40 & 60 & 230 & 1,080 & 1.4 & 274 & 7,200 & 2.6 \\
\hline 20 & 80 & 299 & 1,160 & 1.4 & 359 & 7,700 & 2.3 \\
\hline 0 & 100 & 369 & 1,140 & 1.4 & 442 & 7,200 & 2.5 \\
\hline
\end{tabular}

(1) For experimental details see Tables S3-S8; (2) water content in reactants: dry toluene: 16 ppm, sat. toluene: $520 \mathrm{ppm}, \varepsilon-\mathrm{CL}: 20 \mathrm{ppm}$; ${ }^{(3)}$ SEC in THF (average of triple determination); ${ }^{(4)}$ water content in reactants: dry toluene: 5 ppm, sat. toluene: 547 ppm, $\varepsilon$-CL: 26 ppm.

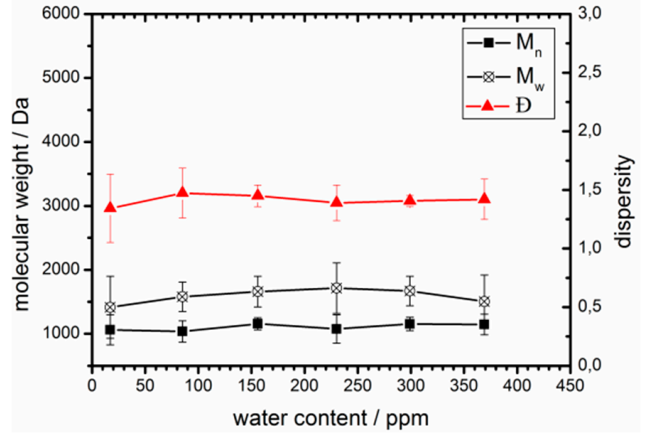

(a)

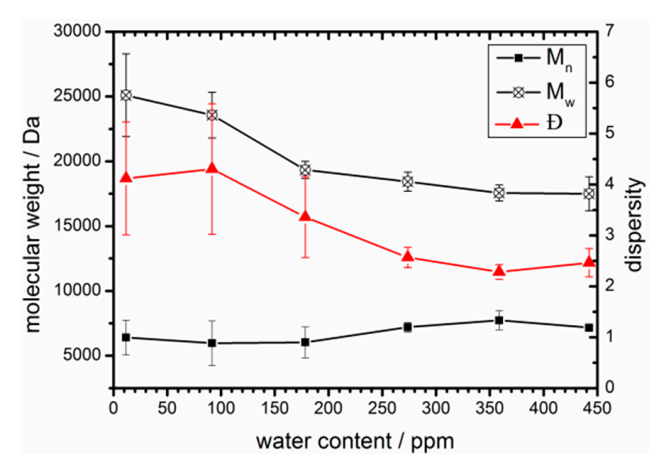

(b)

Figure 3. Enzymatic polymerization of $\varepsilon$-CL with (a) free CaLB and (b) Novozym ${ }^{\circledR} 435$ in toluene with varying water content from 0 to $400 \mathrm{ppm}$. Illustration of the progression of $M_{\mathrm{n}}, M_{\mathrm{w}}$ and $Đ$ with increasing water content.

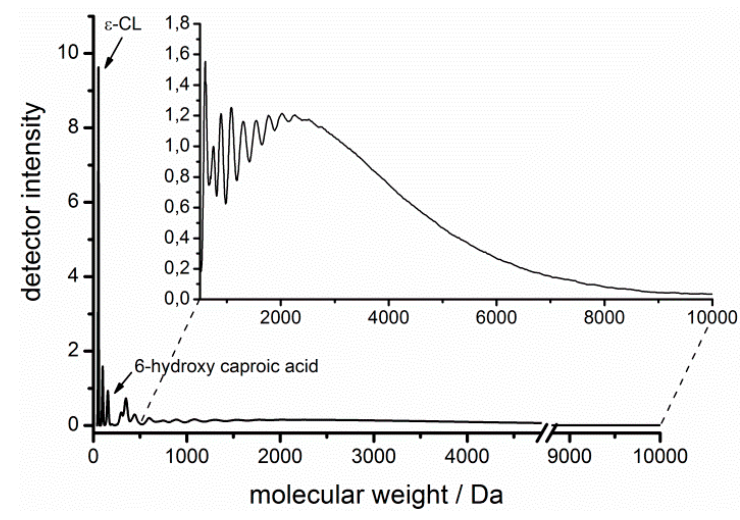

Figure 4. SEC trace for the polymerization of $\varepsilon$-CL in toluene with free CaLB.

In comparison, with Novozym ${ }^{\circledR} 435$ a conversion to polymer of $>90 \mathrm{~mol} \%$ at the equivalent reaction time of $46 \mathrm{~h}$ is obtained, showing the tremendous influence of immobilization on the reactivity and catalytic activity of CaLB. Regarding the SEC trace of the polymerization with Novozym ${ }^{\circledR} 435$ and a water content of $355 \mathrm{ppm}$ (Table S8, No. 5), a multimodal distribution is observed showing both oligomeric and predominantly polymeric products leading to $M_{n} 7800 \mathrm{Da}$ and $Ð 2.3$ (Figure 5, blue line). On closer examination next to the maximum in the overall distribution at $19 \mathrm{kDa}$, two shoulders 
at molecular weights of 1.7 and $6.5 \mathrm{kDa}$ are observed and further a small proportion of high molecular weight products $>40 \mathrm{kDa}$ is found. The overlay of different molecular weight distributions provides an indication for different active sites, i.e., enzymes in different active states. Deconvolution of the original spectrum using MagicPlotPro 2.7 (trial version), neglecting the oligomers, shows, that it can be fitted by exemplarily 5 different Gaussian curves (marked in Figure $5 b$ in yellow, red, green, purple and light blue). The resulting fit sum (orange dashed line) agrees with the experimental SEC trace (adjusted $R^{2}$ value of 0.9996; report of fitting in the supplementary materials, Section 9).

To our best knowledge this multimodal weight distribution has never been reported so far, but from our point of view this is a very important information for the better understanding of the good performance of Novozym ${ }^{\circledR} 435$. We suggest that both the described $\oslash$ values $>2$ as well as the multimodal distributions are ascribed to the different local environments of CaLB in Novozym ${ }^{\circledR} 435$ under the present reaction conditions, resulting in different activities and probabilities for catalysis of esterification or hydrolysis. Fernández-Lafuente et al. explain in their review [28] some of the reasons for the improvements of enzymatic activity, specificity or selectivity by immobilization and scrutinize the comparability of immobilized and free enzymes. One of the main aspects of immobilization is the prevention of aggregation, which can be found for the free enzyme. Further (covalent) immobilization rigidifies the enzymes structure preventing conformational changes by external influences or prevents the deactivation by inhibitors. On the other hand immobilization on a solid support leads to diffusional limitations resulting in e.g., a decreased substrate accessibility or internal $\mathrm{pH}$ gradients. Since immobilization is rather uncontrolled, it is not possible to guarantee the same local environment for all enzyme molecules on a supporting material and therefore enzymes of different activities can be found on the support like the macroporous acrylic resin of Novozym ${ }^{\circledR} 435$. Zhao and Song identified 17 trace compounds leaking from Novozym ${ }^{\circledR} 435$ into organic solvents and ionic liquids which may affect the enzymatic activity of the lipase by behaving as surfactants or inhibitors [32]. It is also worth to mention, that not only trace compounds leak from the acrylic resin, but also the physically adsorbed CaLB tends to leak from the supporting material leading to a small amount of free CaLB [33,34], which may be responsible for the low molecular weight oligomer distribution illustrated in Figure $5 \mathrm{a}$. Another important factor is the interaction of the substrate $\varepsilon$-CL or $\mathrm{P}(\varepsilon-C L)$ respectively with the hydrophobic acrylic resin. It is assumed, that the growing hydrophobic polymer chain interacts more with the supporting material than the monomer or oligomers do. Further due to the increasing length the mobility of the polymer decreases and the diffusion in the supporting material is limited. Therefore longer chains are closer to the enzyme on the supporting material and continue growing, resulting in a small amount of high molecular weight polymers visible in the distribution (light blue Gaussian fit 4).

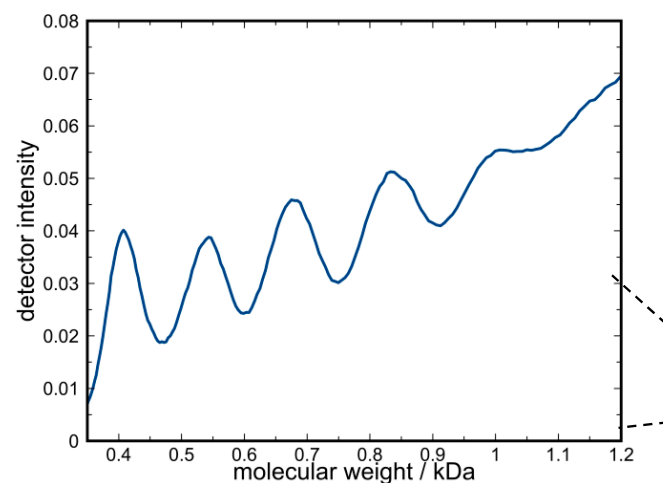

(a)

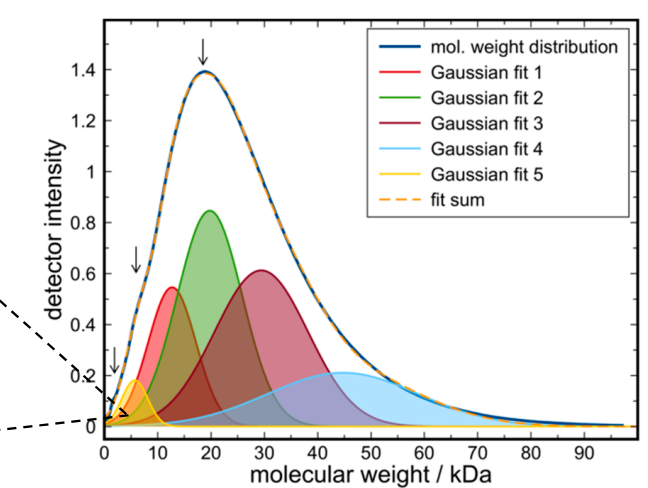

(b)

Figure 5. SEC trace for the polymerization of $\varepsilon$-CL with Novozym ${ }^{\circledR} 435$ in toluene showing (a) the oligomeric fraction; and (b) the high molecular weight fraction including the deconvolution of the original chromatogram by Gaussian fits. 


\subsection{Preparation of Polyglycidol Based Microgels and Immobilization of CaLB}

In the literature, a multitude of methods and materials for enzyme immobilization are described [35,36]. Immobilization by physical adsorption, covalent or ionic binding as well as entrapping on supports from inorganic substances over biopolymers to organic polymers were reported in recent years $[37,38]$. However, the most suitable method for immobilization depends on both the structure of the enzyme and the type of support. In our case the preparation of the microgel in miniemulsion by a prepolymer approach in the way we published recently $[26,27]$ opens the possibility for in situ physical entrapment of CaLB in the crosslinked polymer network (see Scheme 2). Therefore the polyglycidol prepolymer was prepared by sequential anionic polymerization of either $\mathbf{1}$ ethoxyethyl glycidyl ether (EEGE) or $\mathbf{2}$ tert-butylglycidyl ether (tBGE) with allylglycidyl ether (AGE) with a molar ratio of 4:1 using caesium hydroxide and triethylene glycole monomethylether (TEGME) as initiating system based on the publication by Frey et al. [39]. The prepolymers P(EEGE $)_{0.8}-b-\mathrm{P}(\mathrm{AGE})_{0.2} \mathbf{1}$ and $\mathrm{P}(\mathrm{tBGE})_{0.8}-b$-P(AGE) $)_{0.2} 2$ were obtained with $M_{\mathrm{n}} 3600 \mathrm{Da}(\doteq 1.1)$ and $2800 \mathrm{Da}(\doteq 1.1)$ respectively (Figures S5-S10).

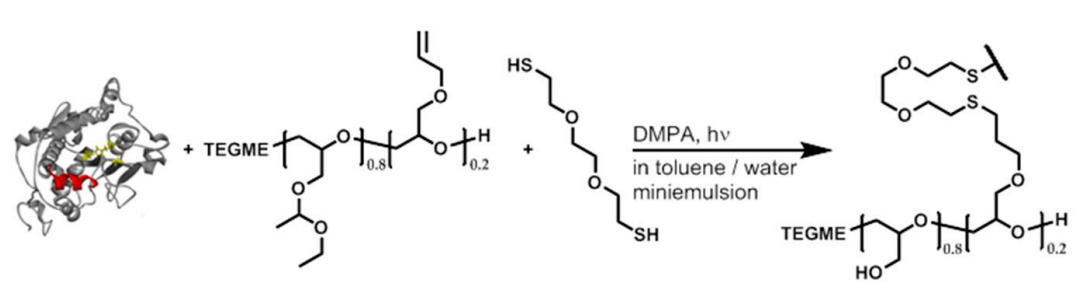

a)

$\mathrm{P}(\mathrm{EEGE})_{0.8}-b-\mathrm{P}(\mathrm{AGE})_{0.2} 1$

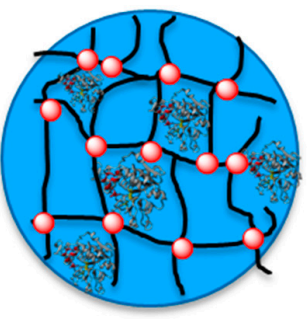

MG 1

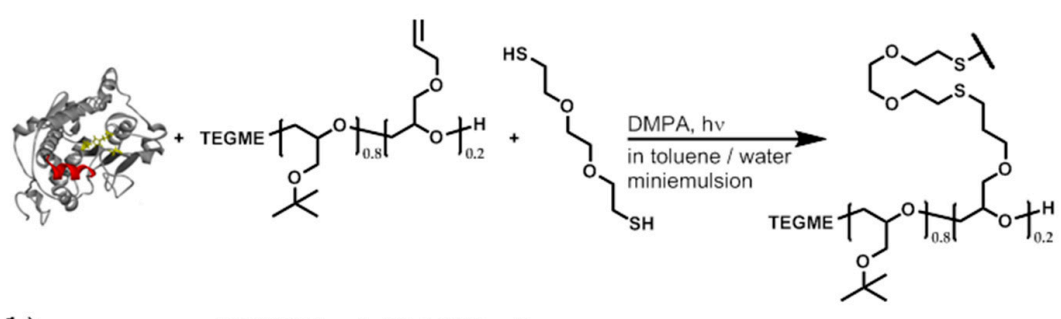

b)

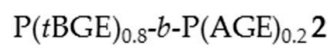

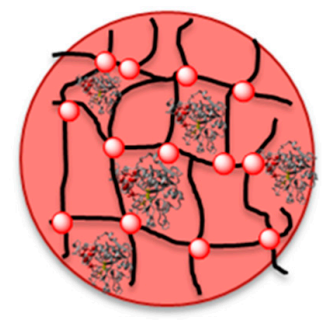

MG 2

Scheme 2. Synthetic route for the preparation of (a) hydrophilic microgels with hydrophobic domains using $\mathrm{P}(\mathrm{EEGE})_{0.8}-\mathrm{b}-\mathrm{P}(\mathrm{AGE})_{0.2} \mathbf{1}$ as prepolymer; and (b) hydrophobic microgels using $\mathrm{P}(t \mathrm{BGE})_{0.8}-b-\mathrm{P}(\mathrm{AGE})_{0.2}$ 2. Free CaLB was entrapped in situ during the microgel synthesis.

For the preparation of the CaLB loaded microgels MG 1 and MG 2 the respective prepolymer 1 or 2 and the CaLB were mixed in toluene with hexadecane as ultrahydrophobe, 2,2-dimethoxy-2-phenylacetophenone (DMPA) as photoinitiator and 2,2'-(ethylenedioxy) diethanethiol as crosslinker. Using sodium dodecylsulfate (SDS) as surfactant an $\mathrm{o} / \mathrm{w}$-miniemulsion of the toluene phase was prepared by ultrasonication. Irradiation of the miniemulsion with UV-light induces the thiol-ene reaction of the dithiol and the allyl moieties of the AGE building block forming a cross-linked network in which the CaLB is entrapped. While the ethoxyethyl acetal protecting group is cleaved in situ during the microgel preparation, the tert-butyl group stays stable under these conditions. Thus, two microgels with different compartmentalizations are formed: a hydrophilic microgel with hydrophobic domains MG 1 and an overall hydrophobic microgel MG 2 (Scheme 2). Both types of microgel were also prepared without CaLB as a reference (MG 1.1 and MG 2.1).

The CaLB concentration in MG 1 and 2 and in Novozym ${ }^{\circledR} 435$ was determined by amino acid analysis. To avoid including not entrapped CaLB into this analytics, the microgels were dialysed against water before. Not only the free CaLB but simultaneously also low molecular weight components, 
which were used in the microgel preparation (e.g., SDS and DMPA), were removed in this washing step. Table 3 shows the average values of a triplicate determination of the loading as well as the theoretical enzyme concentration.

Table 3. Loading efficiency of MG 1 and MG 2 before and after dialysis (MWCO $100 \mathrm{kDa}$ ) and the CaLB-free microgels MG 1.1 and MG 2.1 as well as Novozym ${ }^{\circledR} 435$ as reference.

\begin{tabular}{|c|c|c|c|c|}
\hline \multirow{2}{*}{$\begin{array}{c}\text { Type of supporting } \\
\text { material }\end{array}$} & \multirow{2}{*}{ Prepolymer } & \multirow{2}{*}{ Enzyme } & \multicolumn{2}{|c|}{$[\mathrm{CaLB}] / \mathrm{mg} \cdot \mathrm{mL}^{-1}$} \\
\hline & & & Before dialysis ${ }^{(1)}$ & After dialysis (1) \\
\hline MG 1 & P(EEGE)-b-(PAGE) & CaLB & $0.58(0.54)$ & $0.44(0.48)$ \\
\hline MG 1.1 & $\mathrm{P}(\mathrm{EEGE})-b-\mathrm{P}(\mathrm{AGE})$ & - & 0 & 0 \\
\hline MG 2 & $\mathrm{P}(t \mathrm{BGE})-b-\mathrm{P}(\mathrm{AGE})$ & CaLB & $0.54(0.50)$ & $0.34(0.46)$ \\
\hline MG 2.2 & $\mathrm{P}(t \mathrm{BGE})-b-\mathrm{P}(\mathrm{AGE})$ & - & 0 & 0 \\
\hline acrylic resin (2) & - & CaLB & \multicolumn{2}{|c|}{$0.48^{(3)}$} \\
\hline
\end{tabular}

Even though this method shows a rather broad error margin, two important conclusions can be drawn from the results: (i) It was successful to immobilize CaLB into MG $\mathbf{1}$ and MG $\mathbf{2}$ by physical entrapment independent of the hydrophilic or hydrophobic microgel properties. Both measured averaged lipase concentrations correspond with the theoretical loading with a deviation of 7\%; (ii) Even after threefold dialysis only a small amount of lipase is washed out, whereas the loss is more distinct for the hydrophobic than for the amphiphilic microgel. This different behavior is explained by the variation of the compartmentalization. In MG 1 interfaces between the hydrophilic and the hydrophobic domains are provided where the lipase adsorbs. Since in the overall hydrophobic MG 2 no interfaces are provided, no additional physical attachment occurs. By reengineering the CaLB making it more hydrophobic or using surfactants to increase the interaction of the lipase and the hydrophobic polymer, the problem of enzyme leakage will be overcome in the future. At this point, an important remark to the high error margin of the amino acid analysis has to be done. It is not only the result of systematic errors during the sophisticated sample preparation, but the high deviation of the single measurements rather shows the inhomogeneity of immobilization in general. As described in Section 3.3 it is nearly impossible to load a supporting material with enzyme where firstly a consistent environment is obtained and secondly the homogeneity of the enzyme distribution on or in the support can be controlled.

\subsection{Effect of Immobilization on the Hydrolytic and Esterification Activity of CaLB}

The hydrolytic activities of free and the immobilized CaLB were analyzed by $p$ NPB assay and are shown in Figure 6. For the immobilized CaLB either in a microgel or adsorbed on the acrylic resin in Novozym ${ }^{\circledR} 435$ a strong decrease compared to the free CaLB is determined. While the free CaLB has a hydrolytic activity of $15.1 \mu \mathrm{mol}(\mathrm{min} \cdot \mathrm{mg})^{-1}$ it is reduced in the MG 1 to $3.9 \mu \mathrm{mol}(\mathrm{min} \cdot \mathrm{mg})^{-1}$. Interestingly, the reduction of the hydrolytic activity is much more intense for the hydrophobic MG 2 $\left(1.2 \mu \mathrm{mol}(\mathrm{min} \cdot \mathrm{mg})^{-1}\right)$ and even more for Novozym ${ }^{\circledR} 435\left(0.04 \mu \mathrm{mol}(\mathrm{min} \cdot \mathrm{mg})^{-1}\right)$. Hence, we conclude a correlation between the hydrolytic activity and the hydrophobicity of the supporting material. Additionally, comparing the hydrolytic activities of each microgel before and after dialysis a slightly higher activity after the dialysis is observed in both cases. This is explained by the removal of low molecular weight compounds during the dialysis. SDS, unreacted cross-linker or not cross-linked polymer chains can act as surfactant or inhibitor and therefore decrease the activity of the CaLB. The decrease of hydrolytic activity might be explained either by deactivation of the enzyme or by retardation of the hydrolysis as the local water content in the environment of the lipase is lowered significantly by immobilization. Hence, the question arises whether the decreased activities, which we observed for CaLB entrapped in the amphiphilic MG $\mathbf{1}$ as well as in the hydrophobic MG 2 will be connected to an increased esterification/polymerization activity. 


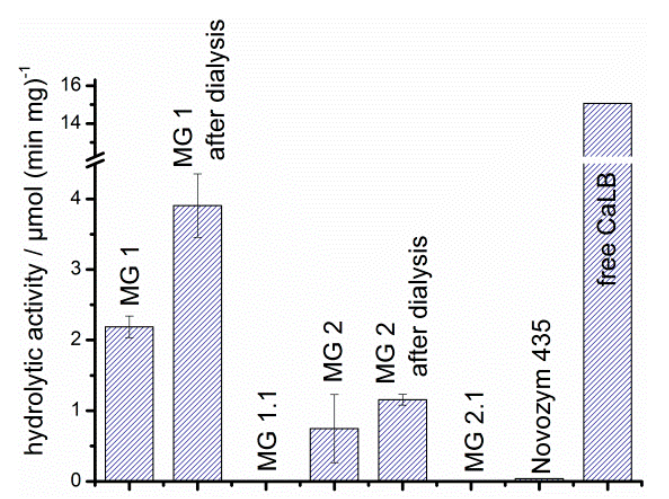

Figure 6. Hydrolytic activity of the CaLB loaded microgels MG 1 and MG 2 before and after dialysis (MWCO $100 \mathrm{kDa}$ ) and the CaLB-free microgels MG 1.1 and MG 2.1 as well as the non-immobilized CaLB as reference.

The esterification ability for the MG 2 and MG 2.1, was investigated for a polymerization of $\varepsilon$-CL in toluene and compared to the identical experiments using free CaLB or Novozym ${ }^{\circledR} 435$ presented in Section 3.3. Therefore, the solvent of the microgels was substituted by dialysis from water to toluene, hereinafter referred to as $\mathrm{MG}_{\mathrm{tol}} 2$ and $\mathrm{MG}_{\mathrm{tol}} 2.1$ respectively. Since the volume was held constant before and after dialysis, the CaLB concentration in $\mathrm{MG}_{\text {tol }} 2$ is also assumed to be constant with an enzyme loading of $0.34 \mathrm{mg} \cdot \mathrm{mL}^{-1}$. Performing the polymerization of $\varepsilon-\mathrm{CL}$ with $1 \mathrm{mg}$ CaLB (2.94 $\left.\mathrm{mL} \mathrm{MG}_{\mathrm{tol}} 2\right)$ a molecular weight for $\mathrm{P}(\varepsilon-\mathrm{CL})$ of $M_{\mathrm{n}} 4900 \mathrm{Da}\left(M_{\mathrm{w}} 11,700 \mathrm{Da}\right)$ and a conversion to the polymeric product of $87 \mathrm{~mol} \%$ was obtained (Table 4, Figure S11). Compared to free CaLB, we observed a huge increase in the conversion to polymer as well as a four times higher molecular weight. While the hydrolytic activity of Novozym ${ }^{\circledR} 435$ was the lowest, the results show that its polymerization ability is even higher than for the $\mathrm{MG}_{\mathrm{tol}}$ 2. Since the reference experiment using enzyme free $\mathrm{MG}_{\mathrm{tol}} \mathbf{2 . 1}$ does not lead to any kind of conversion we proved that the microgel itself has no influence on the initiation of the polymerization (see Table 4, Figure S12).

Table 4. Enzymatic ROP of $\varepsilon$-CL in toluene using free and immobilized CaLB as catalyst; results of NMR and SEC analyses.

\begin{tabular}{|c|c|c|c|c|}
\hline Catalyst & $\mathrm{H}_{2} \mathrm{O}$ content/ppm & $\mathrm{C}_{\text {oligo }} / \mathrm{mol}^{\text {\% }}{ }^{(1)}$ & $M_{n} / \mathrm{Da}^{(2)}$ & $\boxplus^{(2)}$ \\
\hline free CaLB & 369 & 13 & 1,140 & 1.4 \\
\hline Novozym ${ }^{\circledR} 435$ & 359 & 96 & 7,700 & 2.3 \\
\hline $\mathrm{MG}_{\mathrm{tol}} 2$ & 347 & 87 & 4,900 & 2.4 \\
\hline $\mathrm{MG}_{\mathrm{tol}} 2.1$ & 209 & 0 & - (3) & - (3) \\
\hline
\end{tabular}

(1) fraction of $\varepsilon$-CL repeating units determined by ${ }^{1} \mathrm{H}-\mathrm{NMR}$ spectroscopy in $\mathrm{CDCl}_{3}$; ${ }^{(2)} \mathrm{SEC}$ in THF; (3) no oligomers.

These results do not only show that the decrease in hydrolytic activity is not caused by denaturation, but rather that it is an effect of the hydrophobicity of the microenvironment of the supporting material. With increasing hydrophobicity of the supporting material the hydrolytic activity of CaLB is decreased, while simultaneously the polymerization activity is increased.

\section{Conclusions}

In the presented study, we described the successful immobilization of Candida antarctica lipase $B$ in poly(glycidol) based compartmentalized microgels with varying polarity and investigated the influence of immobilization on the hydrolytic and esterification activity of CaLB. Therefore, we first proved the good accessibility of $\varepsilon-\mathrm{CL}$ into toluene as a model, imitating the hydrophobic domain in a microgel $\left(c_{\mathrm{Tol}}^{\mathcal{E}-\mathrm{CL}}=70 \%, \log P_{\mathrm{Tol} / \mathrm{H} 2 \mathrm{O}}=0.37\right)$. Further, we investigated that not the monomer 
concentration, but rather the solubility of CaLB and the water concentration in the hydrophobic medium, which should not exceed $500 \mathrm{ppm}$, play the most important role for the esterification ability. Comparing the polymerization of $\varepsilon$-CL catalyzed by free CaLB and by Novozym ${ }^{\circledR} 435$ in toluene with varying water content, we observed a constant degree of polymerization for free CaLB, while the immobilized form in Novozym ${ }^{\circledR} 435$ gave up to 7 times higher molecular weights. Taking a closer look to the polymerization products for Novozym ${ }^{\circledR} 435$ we observed a multimodal molecular weight distribution and a decreasing dispersity converging from 4 to 2 with increasing water content. These observations are ascribed to the coexistence of CaLB in different local environments on the acrylic resin leading to different polymerization activities. Finally, we prepared amphiphilic and hydrophobic microgels and immobilized CaLB by physical entrapment, which represents an elegant immobilization procedure, since the lipase is entrapped in situ during the microgel preparation. The immobilization was successful in terms of loading efficiency and preservation of enzymatic activity. In both microgels, as well as in Novozym ${ }^{\circledR} 435$, the hydrolytic activity was decreased compared to free CaLB. The intensity of reduction is hereby related to the hydrophilic-lipophilic balance within the microgel, changing the local water content in the close environment of the lipase and retarding the hydrolysis of the substrate. For $\mathrm{MG}_{\text {tol }} 2$ and Novozym ${ }^{\circledR} 435$ we could prove that the reduced hydrolytic activity is simultaneously connected to a strong improvement in esterification ability. Thus, in this work, we have presented an elegant way for CaLB immobilization in microgels and demonstrated a huge effect of the hydrophobicity of the microenvironment of CaLB on the catalytic performance of the lipase.

Supplementary Materials: The following are available online at www.mdpi.com/2073-4360/8/10/372/s1: Figure S1. ${ }^{1} \mathrm{H}-\mathrm{NMR}$ spectrum of $\varepsilon-\mathrm{CL}$ in $\mathrm{D}_{2} \mathrm{O}$ with dioxane standard at $25^{\circ} \mathrm{C}$ (No. 1.1 in Table S1); Figure S2. ${ }^{1} \mathrm{H}-\mathrm{NMR}$ spectrum of $\varepsilon$-CL in toluene- $d_{8}$ with dioxane standard at $25^{\circ} \mathrm{C}$ (No. 1.1 in Table S1); Figure S3. Molar mass distribution for the enzymatic polymerization of $\varepsilon$-CL with CaLB for (a) a ratio of $\varepsilon$-CL and water of $1: 4$ (No. 2.4 in Table S2) and (b) a ratio of $\varepsilon$-CL and toluene 1:4 (No. 2.7 in Table S2); Figure S4. ${ }^{1} \mathrm{H}-\mathrm{NMR}$ spectrum of the polymerization product of experiment No. 2.6 in Table S2 with the signals for the $\varepsilon$-CL monomer (a), the hydrolysis product 6-hydroxyhexanoic acid (b) and the P( $\varepsilon-\mathrm{CL})(\mathrm{c})$; Figures S5-S7. ${ }^{1} \mathrm{H}-\mathrm{NMR}$ and ${ }^{13} \mathrm{C}-\mathrm{NMR}$ spectra as well as SEC trace of P(EEGE) $)_{0.8}-b$-P(AGE) $)_{0.2}$ 1; Figures S8-S10: ${ }^{1} \mathrm{H}-\mathrm{NMR}$ and ${ }^{13} \mathrm{C}-\mathrm{NMR}$ spectra as well as SEC trace of $\mathrm{P}(t \mathrm{BGE})_{0.8}-b-\mathrm{P}(\mathrm{AGE})_{0.2} 2$; Figure S11: (a) SEC trace and (b) ${ }^{1} \mathrm{H}-\mathrm{NMR}$ spectrum for the enzymatic polymerization of $\varepsilon-C L$ with $\mathrm{MG}_{\text {tol }}$ 2; Figure S12: (a) SEC trace and (b) ${ }^{1} \mathrm{H}-\mathrm{NMR}$ spectrum for the enzymatic polymerization of $\varepsilon-C L$ with $M_{\text {tol }}$ 2.1; Table S1: Weights of $\varepsilon-C L, D_{2} \mathrm{O}$, toluene- $\mathrm{d}_{8}$ and dioxane for different temperatures; Table S2: Weights of $\varepsilon-C L, \mathrm{H}_{2} \mathrm{O}$, toluene and $\mathrm{CaLB}$ and the corresponding conversions to polymer $C_{\text {oligo }}$ and molecular weights $M_{\mathrm{n}}$ and $M_{\mathrm{W}}$ determined by ${ }^{1} \mathrm{H}-\mathrm{NMR}$ and SEC; Tables S3-S5: Enzymatic polymerization with CaLB; Tables S6-S8: Enzymatic polymerization with Novozym ${ }^{\circledR}$ 435; Table S9: Weighed portions for the synthesis of P(EEGE)- $b$-P(AGE) 1 based microgels MG 1 and MG 1.1; Table S10: Weighed portions for the synthesis of $\mathrm{P}(t \mathrm{BGE})-b$-P(AGE) 2 based microgels MG 2 and MG 2.1, Section 8. Cloning, production and purification of CaLB, Section 9. Report of deconvolution of the molecular weight distribution obtained with Novozym ${ }^{\circledR} 435$.

Acknowledgments: We thank Deutsche Forschungsgemeinschaft DFG (Sonderforschungsbereich 985 “Functional Microgels and Microgel Systems", Project A1) for their funding of this work. This work was performed in part at the Center for Chemical Polymer Technology CPT, which was supported by the EU and the federal state of North Rhine-Westphalia (grant EFRE 3000883 02). Further we thank Ines Bachmann-Rémy for measuring the temperature dependent ${ }^{1} \mathrm{H}-\mathrm{NMR}$ spectra for the determination of the partition coefficient of $\varepsilon-C L$ in $D_{2} \mathrm{O} /$ toluene- $d_{8}$, Andrea Körner for performing the amino acid analysis for the determination of the amount of entrapped CaLB and Rainer Haas for the SEC measurements.

Author Contributions: The idea for this work comes from Martin Möller und Ulrich Schwaneberg. Within discussion with all authors (Martin Möller, Ulrich Schwaneberg, Helmut Keul, Marco Bocola, Stefan Engel and Heidi Höck the project design was established, results were discussed and interpreted. Design of experiments for cloning, production and purification of CaLB was performed by Heidi Höck, Marco Bocola and Ulrich Schwaneberg. The results of polymer synthesis using CaLB as catalyst were performed, analyzed and interpreted by Stefan Engel, Helmut Keul, and Martin Möller. All experiments were performed by Stefan Engel and Heidi Höck. Presentation of the results and the structure of the manuscript were discussed with all authors; Stefan Engel wrote the first draft and included corrections suggested by the coauthors.

Conflicts of Interest: The authors declare no conflict of interest. 


\section{Abbreviations}

The following abbreviations are used in this manuscript:

\begin{tabular}{|c|c|}
\hline AGE & allyl glycidyl erher \\
\hline CaLB & Candida antarctica lipase B \\
\hline DMPA & 2,2-dimethoxy-2-phenylacetophenone \\
\hline$\varepsilon-C L$ & $\varepsilon$-caprolactone \\
\hline EEGE & ethoxyethyl glycidyl ether \\
\hline$\bigoplus$ & dispersity index \\
\hline MBDSTFA & $N$-methyl-N-tert-butyldimethylsilyl-trifluoroacetamide \\
\hline MG & microgel \\
\hline MTP & microtiterplate \\
\hline PDL & pentadecalactone \\
\hline$p \mathrm{NBP}$ & para-nitrophenol butyrate \\
\hline $\mathrm{ROP}$ & ring opening polymerization \\
\hline SDS & sodium dodecylsulfate \\
\hline tBGE & tert-butyl glycidyl ether \\
\hline TEA & triethanolamine \\
\hline TEGME & triethylene glycol monomethylether \\
\hline UDL & 11-undecanolide \\
\hline YPD & yeast extract peptone dextrose \\
\hline
\end{tabular}

\section{References}

1. Albertsson, A.C.; Varma, I.K. Aliphatic polyesters: Synthesis, properties and applications. Adv. Polym. Sci. 2002, 157, 1-40.

2. Albertsson, A.C.; Varma, I.K. Recent developments in ring opening polymerization of lactones for biomedical applications. Biomacromolecules 2003, 4, 1466-1486. [CrossRef] [PubMed]

3. Zhang, J.; Shi, H.; Wu, D.; Xing, Z.; Zhang, A.; Yang, Y.; Li, Q. Recent developments in lipase-catalyzed synthesis of polymeric materials. Process Biochem. 2014, 49, 797-806. [CrossRef]

4. Reetz, M.T. Lipases as practical biocatalysts. Curr. Opin. Chem. Biol. 2002, 6, 145-150. [CrossRef]

5. Schmid, R.D.; Verger, R. Lipases: Interfacial enzymes with attractive applications. Angew. Chem. Int. Ed. 1998, 37, 1608-1633. [CrossRef]

6. Popescu, D.; Keul, H.; Moeller, M. Poly(meth)acrylates obtained by cascade reaction. Macromol. Rapid Commun. 2011, 32, 559-572. [CrossRef] [PubMed]

7. Vaida, C.; Keul, H.; Möller, M. Tailor-made polyesters based on pentadecalactone via enzymatic catalysis. Green Chem. 2011, 13, 889-899. [CrossRef]

8. Namekawa, S.; Uyama, H.; Kobayashi, S. Lipase-catalyzed ring-opening polymerization of lactones in water. Polym. J. 1998, 30, 269-271. [CrossRef]

9. Schmidt, S.; Scherkus, C.; Muschiol, J.; Menyes, U.; Winkler, T.; Hummel, W.; Gröger, H.; Liese, A.; Herz, H.G.; Bornscheuer, U.T. An enzyme cascade synthesis of $\varepsilon$-caprolactone and its oligomers. Angew. Chem. Int. Ed. 2015, 54, 1-5. [CrossRef] [PubMed]

10. Nallani, M.; de Hoog, H.P.M.; Cornelissen, J.J.L.M.; Palmans, A.R.A.; van Hest, J.C.M.; Nolte, R.J.M. Polymersome nanoreactors for enzymatic ring-opening polymerization. Biomacromolecules 2007, 8, 3723-3728. [CrossRef] [PubMed]

11. Gross, R.A.; Kumar, A.; Kalra, B. Polymer synthesis by in vitro enzyme catalysis. Chem. Rev. 2001, 101, 2097-2124. [CrossRef] [PubMed]

12. Wong, C.-H. Enzymatic catalysts in organic synthesis. Science 1989, 244, 1145-1152. [CrossRef] [PubMed]

13. Jones, J.B. Enzymes in organic synthesis. Tetrahedron 1986, 42, 3351-3403. [CrossRef]

14. Uyama, H.; Kobayashi, S. Enzymatic ring-opening polymerization of lactones catalyzed by lipase. Chem. Lett. 1993, 22, 1149-1150. [CrossRef]

15. Knani, K.; Gutman, A.L.; Kohn, D.H. Enzymatic polyesterification in organic media. Enzyme-catalyzed synthesis of linear polyesters. 1. Condensation polymerization of linear hydroxyesters. II. Ring-opening polymerization of $\varepsilon$-caprolactone. J. Polym. Sci. Part A 1993, 31, 1221-1232. [CrossRef]

16. Uyama, H.; Takeya, K.; Kobayashi, S. Enzymatic ring-opening polymerization of lactones to polyesters by lipase catalyst: Unusually high reactivity of macrolides. Bull. Chem. Soc. Jpn. 1995, 68, 56-61. [CrossRef]

17. Nomura, R.; Ueno, A.; Endo, T. Anionic ring-opening polymerization of macrocyclic esters. Macromolecules 1994, 27, 620-621. [CrossRef] 
18. Lecomte, P.H.; Stassin, F.; Jérôme, R. Recent developments in the ring-opening polymerization of $\varepsilon$-caprolactone and derivatives initiated by tin(IV) alkoxides. Macromol. Symp. 2004, 215, 325-338. [CrossRef]

19. Agarwal, S.; Mast, C.; Dehnicke, K.; Greiner, A. Rare earth metal initiated ring-opening polymerization of lactones. Macromol. Rapid Commun. 2000, 21, 195-212. [CrossRef]

20. De Barros, D.P.C.; Fonseca, L.P.; Cabral, J.M.S.; Aschenbrenner, E.M.; Weiss, C.K.; Landfester, K. Miniemulsion as efficient system for enzymatic synthesis of acid alkyl esters. Biotechnol. Bioeng. 2010, 106, 507-515. [CrossRef] [PubMed]

21. Ragupathya, L.; Pluhara, B.; Ziener, U.; Keller, H.; Dyllick-Brenzinger, R.; Landfester, K. Enzymatic aminolysis of lactones in aqueous miniemulsion: Catalysis through a novel pathway. J. Mol. Catal. B Enzym. 2010, 62, 270-276. [CrossRef]

22. Taden, A.; Antonietti, M.; Landfester, K. Enzymatic polymerization towards biodegradable polyester nanoparticles. Macromol. Rapid Commun. 2003, 24, 512-516. [CrossRef]

23. Weiss, C.K.; Landfester, K. Enzymatic catalysis at interfaces-Heterophase systems as substrates for enzymatic action. Catalysts 2013, 3, 401-417. [CrossRef]

24. Gross, R.A.; Ganesh, M.; Lu, W. Enzyme-catalysis breathes new life into polyester condensation polymerizations. Trends Biotechnol. 2010, 28, 435-443. [CrossRef] [PubMed]

25. Poojari, Y.; Beemat, J.S.; Clarson, S.J. Enzymatic synthesis of poly( $\varepsilon$-caprolactone): Thermal properties, recovery, and reuse of lipase B from Candida Antarctica immobilized on macroporous acrylic resin particles. Polym. Bull. 2013, 70, 1543-1552. [CrossRef]

26. Schulte, B.; Walther, A.; Keul, H.; Möller, M. Polyglycidol-based prepolymers to tune the nanostructure of microgels. Macromolecules 2014, 47, 1633-1645. [CrossRef]

27. Schulte, B.; Rahimi, K.; Keul, H.; Demco, D.E.; Walther, A.; Möller, M. Blending of reactive prepolymers to control the morphology and polarity of polyglycidol based microgels. Soft Matter 2015, 11, 943-953. [CrossRef] [PubMed]

28. Rodrigues, R.C.; Ortiz, C.; Berenguer-Murcia, Á.; Torres, R.; Fernández-Lafuente, R. Modifying enzyme activity and selectivity by immobilization. Chem. Soc. Rev. 2013, 42, 6290-6307. [CrossRef] [PubMed]

29. Fitton, A.O.; Hill, J.; Jane, D.E.; Millar, R. Synthesis of simple oxetanes carrying reactive 2-substituents. Synthesis 1987, 1140-1142. [CrossRef]

30. Inoue, H.; Nojima, H.; Okayama, H. High efficiency transformation of Escherichia coli with plasmids. Gene 1990, 96, 23-28. [CrossRef]

31. Kumar, A.; Gross, R.A. Candida Antartica lipase B catalyzed polycaprolactone synthesis: Effects of organic media and temperature. Biomacromolecules 2000, 1, 133-138. [CrossRef] [PubMed]

32. Zhao, H.; Song, Z. Migration of reactive trace compounds from Novozym ${ }^{\circledR} 435$ into organic solvents and ionic liquids. Biochem. Eng. J. 2010, 49, 113-118. [CrossRef]

33. Sheldon, R.A. Enzyme immobilization: The quest for optimum performance. Adv. Synth. Catal. 2007, 349, 1289-1307. [CrossRef]

34. Idris, A.; Bukhari, A. Immobilized Candida Antarctica lipase B: Hydration, stripping off and application in ring opening polyester synthesis. Biotechnol. Adv. 2012, 30, 550-563. [CrossRef] [PubMed]

35. Rueda, N.; dos Santos, J.C.S.; Ortiz, C.; Torres, R.; Barbosa, O.; Rodrigues, R.C.; Berenguer-Murcia, Á.; Fernández-Lafuente, R. Chemical modification in the design of immobilized enzyme biocatalysts: Drawbacks and opportunities. Chem. Rec. 2016, 16, 1436-1455. [CrossRef] [PubMed]

36. Homaei, A.A.; Sariri, R.; Vianello, F.; Stevanato, R. Enzyme immobilization: An update. J. Chem. Biol. 2013, 6, 185-205. [CrossRef] [PubMed]

37. Sheldon, R.A.; van Pelt, S. Enzyme immobilisation in biocatalysis: Why, what and how. Chem. Soc. Rev. 2013, 42, 6223-6235. [CrossRef] [PubMed]

38. Adlercreutz, P. Immobilisation and application of lipases in organic media. Chem. Soc. Rev. 2013, 42, 6406-6436. [CrossRef] [PubMed]

39. Obermeier, B.; Frey, H. Poly(ethylene glycol-co-allyl glycidyl ether)s: A PEG-based modular synthetic platform for multiple bioconjugation. Bioconjug. Chem. 2011, 22, 436-444. [CrossRef] [PubMed]

(C) 2016 by the authors; licensee MDPI, Basel, Switzerland. This article is an open access article distributed under the terms and conditions of the Creative Commons Attribution (CC-BY) license (http:/ / creativecommons.org/licenses/by/4.0/). 